\title{
Effects of stretching on mechanical properties of aligned multi-walled carbon nanotube/epoxy composites
}

Tran Huu Nam ${ }^{\mathrm{a}^{*}}$, Ken Goto ${ }^{\mathrm{a}}$, Hirokazu Nakayama ${ }^{\mathrm{b}}$, Kahori Oshima ${ }^{\mathrm{c}}$, Vikum Premalal ${ }^{\mathrm{d}}$, Yoshinobu Shimamura $^{\mathrm{d}}$, Yoku Inoue ${ }^{\mathrm{d}}$, Kimiyoshi Naito ${ }^{\mathrm{e}}$, Satoshi Kobayashi ${ }^{\mathrm{f}}$

${ }^{a}$ Department of Space Flight Systems, Institute of Space and Astronautical Science, Japan Aerospace Exploration Agency, 3-1-1 Yoshinodai, Chuo, Sagamihara, Kanagawa 252-5210, Japan

${ }^{\text {b } G r a d u a t e ~ S t u d e n t, ~ A o y a m a ~ G a k u i n ~ U n i v e r s i t y, ~ 5-10-1 ~ F u c h i n o b e, ~ C h u o, ~ S a g a m i h a r a, ~ K a n a g a w a ~ 252-~}$ 5258, Japan

c Graduate Student, Shizuoka University, 3-5-1 Johoku, Naka-ku, Hamamatsu, Shizuoka 432-8561, Japan

${ }^{\mathrm{d}}$ Faculty of Engineering, Shizuoka University, 3-5-1 Johoku, Naka-ku, Hamamatsu, Shizuoka 432-8561, Japan

e National Institute for Materials Science, 1-2-1 Sengen, Tsukuba, Ibaraki 305-0047, Japan

${ }^{\mathrm{f}}$ Department of Mechanical Engineering, Tokyo Metropolitan University, 1-1 Minami-Osawa, Hachioji, Tokyo 192-0397, Japan

${ }^{*}$ Corresponding author: Fax: +81 (0)42-759-8431

E-mail: tran.huunam@jaxa.jp (Tran Huu Nam)

\section{ABSTRACT}

Composites based on epoxy resin and differently aligned multi-walled carbon nanotube (MWCNT) sheets have been developed using hot-melt prepreg processing. Aligned MWCNT sheets were produced from MWCNT arrays using the drawing and winding technique. Wavy MWCNTs in the sheets have limited reinforcement efficiency in the composites. Therefore, mechanical stretching of the MWCNT sheets and their prepregs was conducted for this study. Mechanical stretching of the MWCNT sheets and hot stretching of the MWCNT/epoxy prepregs markedly improved the mechanical properties of the composites. The improved mechanical properties of stretched 
composites derived from the increased MWCNT volume fraction and the reduced MWCNT waviness caused by stretching. With a 3\% stretch ratio, the MWCNT/epoxy composites achieved their best mechanical properties in this study. Although hot stretching of the prepregs increased the tensile strength and modulus of the composites considerably, its efficiency was lower than that of stretching the MWCNT sheets.

Keywords: A. Nano-structures; A. Polymer-matrix composites (PMCs); B. Mechanical properties; E. Prepreg

\section{Introduction}

Carbon nanotubes (CNTs), discovered in 1991 [1] and regarded as molecular-scale tubes of graphite carbon, are classifiable into single-walled CNTs (SWCNTs) and multiwalled CNTs (MWCNTs) [2,3]. Because of their superior performance, CNTs have attracted much interest for use in widely diverse applications. They have high mechanical properties [4-7], high electrical conductivity [8], and high thermal conductivity [9]. Research results have revealed CNTs as excellent reinforcement agents for the next generation of high-performance structural materials. However, largescale applications of individual CNTs remain challenging because of CNTs' poor processability and difficulty of structural control. To enable practical applications of CNTs, bulk CNT reinforced polymer composite materials have been developed and assessed [10-12].

Studies of CNTs as reinforcing agents of polymer composites have been conducted during the last two decades. Methods to produce CNT-reinforced polymer composites have included (1) dispersing short CNTs [13,14], (2) reinforcing CNT arrays [15-17], fibers and yarns [18,19], buckypapers [20,21], and sheets with polymer matrix. 
Moreover, several approaches such as shear-pressing [22] and domino-pushing [23] have been developed to produce aligned CNT preforms that are applicable to fabricate CNT composites. These aligned CNT composites have exhibited better properties than those obtained from CNT dispersions and buckypaper composites, but their mechanical properties fall far short of traditional high-performance structural composites.

Recently, great efforts have been made to produce horizontally aligned CNT sheets from vertically aligned CNT arrays [24-30]. Highly oriented aligned CNT sheets have been particularly promising for use as reinforcement for high-performance composites [24,25]. Using aligned CNT sheets, Cheng et al. [26,27] produced unidirectional CNT/epoxy composites with tensile strength (TS) of $231 \mathrm{MPa}$ and elastic modulus (EM) of 20.4 GPa. Ogasawara et al. [29] also developed unidirectional CNT/epoxy composites with maximal TS of $181 \mathrm{MPa}$ and EM of $50.1 \mathrm{GPa}$. Although the composites produced as described above contain aligned CNTs, their mechanical properties are inadequate partly because of wavy and entangled CNTs. The wavy CNTs do not carry the load efficiently and cannot be packed densely, leading to low stiffness and strength of the resulting composites. Therefore, mechanical stretching has been applied to the aligned CNT sheets [28] and composites [30] to improve the composite properties.

For this study, horizontally long-aligned MWCNT sheets were produced from vertically aligned MWCNT arrays using a drawing and winding technique. Aligned MWCNT sheet reinforced epoxy composites were developed using hot-melt prepreg processing. The hot-melt prepreg processing can maintain the alignment of MWCNTs during resin impregnation. Mechanical stretching was applied to both MWCNT sheets and their prepregs to reduce wavy MWCNTs for improvement of the composite 
properties. Effects of stretching on the mechanical properties of the composites were investigated. The MWCNT volume fractions were ascertained using thermogravimetric analysis (TGA). Field emission scanning electron microscopy (FE-SEM) was used to investigate the respective microstructures of the MWCNT sheets.

\section{Experimental}

\subsection{Materials}

Inoue et al. rapidly grew vertically aligned MWCNT arrays with about $0.8 \mathrm{~mm}$ height on a bare quartz substrate using chloride mediated chemical vapor deposition with single gas flow of acetylene only [17]. The mean diameter of MWCNTs used for this study was $40 \mathrm{~nm}$ [19]. The B-stage epoxy resin sheet covered with release paper and plastic film was obtained from Sanyu Rec Co. Ltd. (Osaka, Japan) with the recommended cure condition of $130^{\circ} \mathrm{C}$ for $2 \mathrm{~h}$. The areal weight of B-stage epoxy resin sheet with density of $1.2 \mathrm{~g} / \mathrm{cm}^{3}$ is about $12 \mathrm{~g} / \mathrm{m}^{2}$.

\subsection{Processing of horizontally aligned MWCNT sheets}

A solid-state drawing and winding technique was applied to transform a vertically aligned MWCNT array into horizontally aligned MWCNT sheets. The MWCNT webs were easily drawn and stacked together to form horizontally aligned MWCNT sheets. Fig. 1 portrays the processing of a horizontally aligned MWCNT sheet by drawing and winding MWCNT webs on a rotating spool. As-stacked aligned MWCNT sheets were densified by spraying ethanol, which was then evaporated. Detailed procedures for the fabrication of MWCNT sheets are described in the literature [17,25,29]. In this study, aligned MWCNT sheets with 20, 50, and 100 plies were used for composite fabrication.

\subsection{Fabrication of aligned MWCNT/epoxy prepregs and the composites}


A stacked aligned MWCNT sheet of $20 \mathrm{~mm}$ width and $50 \mathrm{~mm}$ length was covered with an epoxy resin sheet and set in two release films (WL5200; Airtech International Inc., CA, USA) to produce a prepreg. The prepregs were fabricated under 0.5 MPa pressure for 5 min at $100{ }^{\circ} \mathrm{C}$ using a test press (MP-WNL; Toyo Seiki Seisaku-Sho Ltd., Tokyo, Japan). Subsequently, the prepregs were peeled off from the release films and release paper. Finally, the prepregs were placed between two release films and were cured at $130{ }^{\circ} \mathrm{C}$ for $2 \mathrm{~h}$ under $1 \mathrm{MPa}$ to produce the composites. The non-stretched prepregs and composites are designated respectively as $\mathrm{PX}$ and $\mathrm{CX}$, in which $\mathrm{X}$ corresponds to nonstretched (as-received) MWCNT plies in number (20, 50, and 100).

\subsection{Mechanical stretching the aligned MWCNT sheets and the prepregs}

In this study, mechanical stretching with ratios of $2-4 \%$ was applied to as-received MWCNT sheets and their prepregs to reduce wavy MWCNTs in the composites. The stretch ratio $\Delta$ was calculated using the following equation.

$$
\Delta=\frac{L_{2}-L_{1}}{L_{1}}
$$

In that equation, $L_{1}$ and $L_{2}$ respectively denote the segment lengths of MWCNT sheets and prepregs between the clamped grips before and after stretching. A schematic illustration of the stretching device with a mounted sample is presented in Fig. 2. The stretching device consists of a base plate with two guidance grooves, a long screw, a fixed block and a movable block. A millimeter-scale ruler is secured to a sidewall of the base plate (Fig. 2). This ruler is used only to determine the approximate displacement of the movable block. The precise displacement of the movable block was determined using a Vernier caliper with accuracy of $0.02 \mathrm{~mm}$. The distance between the fixed block and the movable block was fixed initially at $40 \mathrm{~mm}$, which was designated as length $L_{1}$. The MWCNT sheet and prepreg samples with $50 \mathrm{~mm}$ length were mounted on the 
stretching device, as presented in Fig. 2. With stretch ratios of 2, 3, and 4\%, the respective displacements of the movable block are $0.8,1.2$, and $1.6 \mathrm{~mm}$. The displacement rate for stretching is about $0.2 \mathrm{~mm} / \mathrm{min}$. It is noteworthy that hot stretching of the prepregs was conducted inside a drying oven (DVS602; Yamato Scientific Co. Ltd., Tokyo, Japan) to maintain precise temperature control.

\subsection{Thermogravimetric analysis}

The thermal degradation characteristics of epoxy resin, MWCNT sheets, their prepregs, and composites were analyzed up to $800{ }^{\circ} \mathrm{C}$ in a purging nitrogen gas with a flow rate of $100 \mathrm{ml} / \mathrm{min}$ using a thermogravimetric analyzer (STD 2960; TA Instruments, Delaware, USA). About $5 \mathrm{mg}$ of each specimen was loaded for each measurement at a heating rate of $10^{\circ} \mathrm{C} / \mathrm{min}$.

\subsection{Material characterization and testing}

Tensile tests were conducted for the MWCNT sheets, their prepregs, and composites in the laboratory environment at room temperature (RT). For the MWCNT sheets and their prepregs, tensile samples with about $10 \mathrm{~mm}$ gauge length and $5 \mathrm{~mm}$ width were tested on a testing machine (EZ-L; Shimadzu Corp., Kyoto, Japan) with a load cell of $50 \mathrm{~N}$ and a crosshead speed of $0.05 \mathrm{~mm} / \mathrm{min}$. For the composites, tensile specimens with about $6 \mathrm{~mm}$ gauge length and $3 \mathrm{~mm}$ width were tested with a crosshead speed of 0.1 $\mathrm{mm} / \mathrm{min}$. The sample width was measured using an optical microscope (SZX12; Olympus Corp., Tokyo, Japan). Its thickness was measured using a micrometer with 0.001 mm accuracy (102-119; Mitutoyo Corp., Kanagawa, Japan). The thickness measurements using this micrometer were conducted carefully to minimize the measurement error. The strain was measured using a non-contacting video extensometer (TRIViewX; Shimadzu Corp., Kyoto, Japan) with two targets. Mean tensile properties 
were obtained from at least five specimens. The microstructure of the MWCNT sheets was observed using FE-SEM (SU8030; Hitachi Ltd., Tokyo, Japan).

\section{Results and discussion}

\subsection{MWCNT volume fraction}

The MWCNT volume fraction of non-stretched composites was determined from TGA as follows: First the respective mass losses of epoxy resin, non-stretched MWCNT sheets and composites were measured between $150^{\circ} \mathrm{C}$ and $750{ }^{\circ} \mathrm{C}$. Subsequently, the MWCNT mass fraction $\left(m_{f}\right)$ of the composites was calculated from the mass loss of the $\operatorname{MWCNTs}\left(\Delta m_{f}\right)$, epoxy resin $\left(\Delta m_{m}\right)$, and the composite $\left(\Delta m_{c}\right)$ as shown below.

$$
m_{f}=\frac{\left(\Delta m_{m}-\Delta m_{c}\right)}{\left(\Delta m_{m}-\Delta m_{f}\right)}
$$

The MWCNT volume fraction $\left(V_{f}\right)$ was finally determined from the mass fraction of the MWCNTs, epoxy resin density $\left(\rho_{m}\right)$, and density of the composite $\left(\rho_{c}\right)$, as

$$
V_{f}=1-\frac{\left(1-m_{f}\right) \rho_{c}}{\rho_{m}} .
$$

For the stretched composites, we estimated the MWCNT volume fraction $\left(V_{f}^{s}\right)$ through

its thickness $\left(h_{s}\right)$ and width $\left(w_{s}\right)$, stretch ratio $(\Delta)$, and MWCNT volume fraction $\left(V_{f}^{n}\right)$, thickness $\left(h_{n}\right)$ and width $\left(w_{n}\right)$ of the non-stretched composite, as shown below.

$$
V_{f}^{s}=\frac{h_{n}}{(1+\Delta) h_{s} t} V_{f}^{n} ; t=\frac{w_{s}}{w_{n}}
$$

Therein, $t$ can be regarded as a width change ratio between the respective stretched and non-stretched MWCNT sheets. With stretch ratios of 2, 3, and 4\%, the respective mean width changes between the stretched and non-stretched MWCNT sheets are 0.998, 0.995, and 0.988. The thickness and MWCNT volume fraction of non-stretched and 
stretched composites are presented in Table 1. With increasing stretch ratio, the stretched composite thickness decreased, but the MWCNT volume fraction increased. The reduction of stretched composite thickness can be attributed to dense packing of the MWCNT sheets caused by stretching. Once the MWCNT sheets are stretched, they tend to contract in the directions transverse to the stretching direction. Therefore, the thickness of stretched MWCNT sheets decreased to less than that of the non-stretched ones. That decreased composite thickness markedly increases the MWCNT volume fraction.

\subsection{Properties of non-stretched MWCNT sheets, their prepregs and composites} Typical stress-strain curves of non-stretched MWCNT sheets and their prepregs are displayed in Fig. 3. The stress-strain curves of non-stretched MWCNT sheets in Fig. 3a showed that sliding of MWCNTs in the sheets probably occurred in the non-elastic behavior portion, as presented by Inoue et al. [25]. The stress-strain curves of the MWCNT/epoxy prepregs in Fig. 3b showed that fracture occurred suddenly at the maximal load. In addition, tensile testing of non-stretched MWCNT/epoxy composite specimens indicated the linear stress-strain relation until fracture. The properties of nonstretched MWCNT sheets, their prepregs and composites are shown in Tables 2 and 3. Results show that mechanical properties of the prepregs exhibited a higher EM, and lower TS and FS in comparison with corresponding MWCNT sheets.

As Table 2 shows, the areal weight and thickness of non-stretched MWCNT sheets were enhanced progressively with increase of the MWCNT plies. Moreover, TS and EM of the MWCNT sheets increased gradually with increase of the MWCNT plies, although the strain at maximal stress decreased slightly. Compared to the 20-ply MWCNT sheet, the 100-ply MWCNT sheet exhibited an increase in TS by 50\% and in 
EM by $53 \%$. Simultaneously, a decrease in the strain at maximal stress by $14 \%$ was evident. It is particularly interesting that the properties of the prepregs and composites vary similarly to those of the MWCNT sheets when the MWCNT plies are increased from 20 to 100 (Tables 2 and 3). The P100 and C100 respectively exhibited an increase in TS by $39 \%$ and $114 \%$, in EM by $111 \%$ and $199 \%$, and a decrease in the fracture strain (FS) by $28.9 \%$ and $28.8 \%$ compared with the P20 and C20. The enhancement of TS and EM is attributable to the increase of the MWCNT volume fraction (Table 1). The decrease in FS can be attributed mainly to the addition of high MWCNT content, leading to reduction in the amount of epoxy matrix available for the elongation.

\subsection{Effect of stretching the MWCNT sheets on composite properties}

As depicted in Fig. 3a under tension, the stress and strain relation of the MWCNT sheets is regarded as linear with increasing strain to about $2 \%$. In addition, the strain at maximal stress of the MWCNT sheets was 3-4\%. As a result, the MWCNT sheets were stretched with the ratios of 2, 3, and $4 \%$ at RT using the stretching device (Fig. 2). The stretched MWCNT sheets mounted on the stretching device were impregnated immediately with B-stage epoxy resin to create stretched MWCNT/epoxy prepregs. Subsequently, the stretched prepregs were cured in a hot press to produce stretched MWCNT/epoxy composites. Tensile testing of the stretched MWCNT/epoxy composites showed the linear stress-strain relation until fracture, similarly to the nonstretched ones. Effects of stretching the MWCNT sheets on mechanical properties of the composites are presented in Fig. 4. FE-SEM micrographs of non-stretched and stretched MWCNT sheets are displayed in Fig. 5.

As Fig. 4 shows, TS and EM of the composites increased concomitantly with increase of the stretch ratio up to $3 \%$, but they decreased with a $4 \%$ stretch ratio. The 
enhancement in TS and EM of stretched composites might be attributable to the increase of the MWCNT volume fraction (see Table 1) and the reduction of the wavy MWCNTs caused by stretching. The wavy MWCNTs are clearly visible in Fig. 5a, but they are reduced considerably after $2 \%$ stretching (Fig. 5b), thereby improving the mechanical properties of the MWCNT/epoxy composites (see Fig. 4). Furthermore, most wavy MWCNTs had disappeared in the case of 3\% stretching, resulting in high alignment, dense packing, and straightening of the MWCNTs (Fig. 5c). Therefore, the mechanical properties of 3\% stretched MWCNT/epoxy composites greatly improved. The MWCNTs are self-assembled and straightened along the load direction during stretching. Consequently, the dense packing of MWCNTs in the stretched sheets (Figs. 5b-5d) became more compact than that in the non-stretched MWCNT sheets (Fig. 5a). Compared with non-stretched composites, 3\% stretched composites reinforced with 20, 50, and 100 MWCNT plies have remarkably higher TS of 184.1, 307.0, and 448.6 MPa and higher EM of 33.2, 53.2, and 67.9 GPa, respectively corresponding to 86, 110, and $112 \%$ enhancement of TS and 84, 52, and 26\% improvement of EM.

Nevertheless, with a 4\% stretch ratio, the TS and EM of stretched composites decreased considerably (Figs. 4a-4b) even if the MWCNT volume fraction was enhanced (Table 1). This decrease is explainable by the sliding behavior of several MWCNTs leading to a marked reduction in the effective strength and modulus of the composites. In addition, the maximal stress of the MWCNT sheets achieved less than 4\% strain (see Fig. 3a and Table 2). Moreover, the split without breaking into separate parts of MWCNT sheets during stretching with the ratio of $4 \%$ occurred, especially close to clamped grips (Fig. 6d). Stretching of the MWCNT sheet is apparent in Figs. 6b-6c, although splitting without breakage can be observed in Fig. 6d. Therefore, the 
load transfer efficiency of $4 \%$ stretched MWCNTs in the composites is expected to decline, thereby decreasing the mechanical properties of the composites.

With an increase of the MWCNT plies, the FS of non-stretched composites decreased, although the FS of stretched composites is slightly enhanced. Evidently, the stress and strain relation of the composites was linear until fracture. Therefore, the variation of FS depended dramatically on the changes of TS and EM. For instance, 2\% stretched composites reinforced with 20 MWCNT plies showed an increase in TS to $124 \mathrm{MPa}$ by just 25\%, although that in EM increased by 60\% compared with nonstretched composites. For that reason, the FS was reduced considerably (approximately 21\%). Furthermore, the FS of stretched MWCNT/epoxy composites depends on the stretch ratio following similar trends to those of TS and EM. The FS of stretched composites with 50 and 100 MWCNT plies was enhanced with the increase of the stretch ratio up to 3\%, but it was reduced with a 4\% stretch ratio (Fig. 4c). For example, with reinforced 100 MWCNT plies, a 3\% stretched composite exhibited an increase in TS by 36\% and in EM by 8\% only. Consequently, its FS was enhanced considerably from $0.53 \%$ to $0.66 \%$ compared with a $2 \%$ stretched composite.

Fracture surfaces of the non-stretched and stretched MWCNT/epoxy composites are presented in Fig. 7. The FE-SEM micrographs in Fig. 7 show that epoxy resin infiltrated well between the MWCNTs. However, many pulled-out MWCNTs are visible in Fig. 7. The pulled-out length was apparently a few micrometers. Because the MWCNT array height was about $0.8 \mathrm{~mm}$, the MWCNTs evidently were broken in the matrix $[27,29]$. In addition, many MWCNT bundles appeared on the fracture surfaces of the stretched composites (Figs. 7c-7d). The appearance of MWCNT bundles is attributable to the straightening of the MWCNTs caused by stretching (see Fig. 5). Moreover, several 
MWCNTs were pulled out from the fracture surfaces with clearly smaller diameter at the end of breaking point (Fig. 7d). That phenomenon can be attributed sword-in-sheath failure of MWCNTs [7] in which the broken outer walls were pulled-out, leaving intact inner walls in the epoxy matrix. The sword-in-sheath failure occurs easily because the MWCNTs in this study have quite large diameter.

To evaluate the approximate effectiveness of the stretching, the straight, wavy, and entangled MWCNTs on the surfaces of the non-stretched and stretched MWCNT sheets were counted from the FE-SEM images (see Fig. 5). The straight, wavy, and entangled MWCNTs were specified through their orientation angle. The respective orientation angles of the straight, wavy, and entangled MWCNTs vary from $0^{\circ}$ to about $10^{\circ}$, from $10^{\circ}$ to about $45^{\circ}$, and from $45^{\circ}$ to $90^{\circ}$. Results show that, with more than 500-MWCNT count, the respective percentages of straight, wavy, and entangled MWCNTs on the surfaces of the non-stretched MWCNT sheets are about 20,60, and 20\%. After stretching of the MWCNT sheets, the percentage of the straight MWCNTs increased drastically to about 70\%, although the wavy MWCNT percentage decreased considerably to about $10 \%$. In addition, the percentages of the entangled MWCNTs in the sheets before and after stretching differed slightly. In general, the non-stretched composite showed many wavy MWCNTs along the axial loading direction. Therefore, just a small fraction of MWCNTs in the composite carries the load effectively during tensile testing. After mechanical stretching, the wavy MWCNTs in the sheet were straightened. Those straightened MWCNTs have a larger fraction of their length aligned with the loading direction, which caused higher mechanical strength and stiffness [30]. In this study, mechanical properties of stretched MWCNT/epoxy composites reached their highest values with the 3\% stretch ratio. Maximum TS and EM of the 
MWCNT/epoxy composites in this study were achieved as $448.6 \mathrm{MPa}$ and $67.9 \mathrm{GPa}$, respectively, which were 8.1 and 26.6 times higher than those of the epoxy resin.

\subsection{Effects of hot stretching the prepregs on composite properties}

The maximal FS of the MWCNT/epoxy prepregs measured at RT is low (see Table 2). Concurrently, fracture of the prepregs occurs unexpectedly (Fig. 3b). Therefore, mechanical hot stretching of the prepregs is efficient. Once B-stage epoxy resin is heated to $60^{\circ} \mathrm{C}$, it will tend to soften and begin to melt. Additionally, heating can reduce the viscosity of B-stage epoxy resin in the MWCNT/epoxy prepregs and thereby allow the MWCNTs to straighten during stretching. In this study, 2\% hot stretch of P20 at 60,80 , and $100{ }^{\circ} \mathrm{C}$ for 30 min was conducted first to determine the most reasonable temperature for hot stretching. Subsequently, hot stretching with different ratios was conducted at this temperature for other prepregs. Finally, the influence of hot stretching on the mechanical properties of the MWCNT/epoxy composites was evaluated.

Effects of mechanical hot stretching the 20-ply MWCNT/epoxy prepregs at different temperatures on TS and EM of their composites are presented in Fig. 8. TS and EM of the composite were enhanced with the increase of temperatures from $60{ }^{\circ} \mathrm{C}$ to $100{ }^{\circ} \mathrm{C}$, although FS changed slightly between $0.48 \%$ and $0.49 \%$. TS and EM of the hotstretched composite rapidly increased respectively from $113.5 \mathrm{MPa}$ and $23.8 \mathrm{GPa}$ at $60{ }^{\circ} \mathrm{C}$ to $121.6 \mathrm{MPa}$ and $24.9 \mathrm{GPa}$ at $80^{\circ} \mathrm{C}$. At $60{ }^{\circ} \mathrm{C}$, uncured epoxy resin just starts to soften. Therefore, straightening of the MWCNTs in the prepreg can be limited by the constraint from B-stage epoxy resin. Once the temperature increases to $80^{\circ} \mathrm{C}$, the $\mathrm{B}$ stage epoxy resin is melted, which increases the straightening ability of MWCNTs in the prepregs during stretching. Consequently, hot stretching at $80^{\circ} \mathrm{C}$ probably reduced the waviness of MWCNTs strongly, thereby enhancing TS and EM of the composites. 
When the temperature increases from $80{ }^{\circ} \mathrm{C}$ to $100{ }^{\circ} \mathrm{C}$, TS and EM of the composites rose slightly to $122.6 \mathrm{MPa}$ and $25.4 \mathrm{GPa}$, respectively, with just $0.8 \%$ and $1.8 \%$ enhancement. Results show that $100{ }^{\circ} \mathrm{C}$ can be regarded as a reasonable temperature for the following investigations.

To improve the mechanical properties of the MWCNT/epoxy composites, hot stretching of the MWCNT/epoxy prepregs (P20, P50 and P100) with ratios of $2 \%$ and $3 \%$ was performed at $100{ }^{\circ} \mathrm{C}$ for $30 \mathrm{~min}$. Efforts to carry out $4 \%$ hot stretching the prepregs were not successful because of breakage close to the clamped grips. The effect of hot stretching the prepregs on mechanical properties of the composites is depicted in Fig. 9. The values of TS and EM of the composites increased gradually with increase of the number of MWCNT plies (Figs. 9a-9b). Evidently, the increase of MWCNT loading engenders enhancement in TS and EM of the composites. Compared to the composite reinforced with 20 MWCNT plies, 2\% and 3\% hot-stretched composites reinforced with 100 MWCNT plies enhanced in TS by 118 and 94\% and in EM by 137 and $115 \%$, respectively. The FS of the composites with 50 and 100 MWCNT plies has the same trend as those of TS and EM. Nevertheless, the change of FS for the composite with 20 MWCNT plies was not clear (Fig. 9c).

Moreover, the hot-stretched composites exhibited higher TS and EM than those of non-stretched composites (Figs. 9a-9b). The 3\% hot-stretched composite reinforced with 20, 50, and 100 MWCNT plies showed respective increases in TS of 70, 88, and 55\% and in EM of 62, 41, and 16\% compared with corresponding non-stretched ones. The increase of TS and EM is attributable to reduction of the wavy MWCNTs in the composites caused by hot stretching, as explained above. However, hot stretching the prepregs showed a lower TS and EM of the composites compared to mechanical 
stretching the MWCNT sheet at RT (see Figs. 4 and 9). This difference is explainable by the fact that straightening the MWCNTs in the prepregs was limited by constraint from melted B-stage epoxy, as described above. Overall, hot stretching the prepregs at different temperatures improved the mechanical properties of the MWCNT/epoxy composites considerably. Nevertheless, the effectiveness of hot stretching the prepregs is lower than that of mechanical stretching the MWCNT sheets because of lower mechanical properties. Consequently, mechanical stretching the MWCNT sheets should be chosen to improve their composite properties.

\subsection{Evaluating the effect of volume fraction change}

As presented above, increasing the TS and EM of stretched composites probably originated from enhancement of the MWCNT volume fraction and from reduction of the wavy MWCNTs, which are attributable to stretching. The respective percentage increases of EM and MWCNT volume fraction changes of stretched composites compared with those of non-stretched ones were analyzed to evaluate the effects of these two factors. The results are presented in Fig. 10. In general, the percentage increase of EM by the enhanced MWCNT volume fraction was lower than that of the total EM. At low MWCNT content (20 plies) the percentage increase of EM (40-84\%) was much higher than that of the volume fraction (12-30\%). At low MWCNT loading, the percentage of volume fraction enhancement was approximately one-third of the EM increase in percentage terms. This difference is explainable by the fact that the MWCNTs in 20-ply sheets were straightened easily during stretching, leading to marked enhancement of composite properties in spite of the slight increase of the MWCNT volume fraction. Therefore, the volume fraction increase of the stretched 
composites with low MWCNT content was probably less efficient than reducing the MWCNT waviness caused by stretching.

For high MWCNT loading (50 and 100 plies), the percentage increase of the MWCNT volume fraction in the cases of $2 \%$ and $3 \%$ stretching was greater than onehalf of EM (Fig. 10). For instance, the 3\% stretched composites with 50 MWCNT plies showed a $52.1 \%$ increase of EM and a 27.6\% enhancement of the MWCNT volume fraction (Fig. 10a). Nevertheless, in the case of 4\% stretching of the MWCNT sheets, the percentage increase of the volume fraction of the composites with 100 MWCNT plies was higher than that of EM. This difference might be attributable to the splitting of MWCNTs in sheets during stretching, as explained above. Consequently, the volume fraction increase of the stretched composites with high MWCNT loading was probably more efficient than reducing the MWCNT waviness. Moreover, the volume fraction increase in the percentage of the composites with high MWCNT contents is lower than that with low MWCNT loading. Overall, the increase of the volume fraction and the reduction of the wavy MWCNTs caused by mechanical stretching strongly affected the improvement of the composite properties.

\section{Conclusions}

The aligned MWCNT/epoxy composites were developed using hot-melt prepreg processing. The drawing and winding technique was applied to produce aligned MWCNT sheets, whereas mechanical stretching was used to reduce the wavy MWCNTs in the sheets. Mechanical stretching the MWCNT sheets and hot stretching their prepregs greatly improved the mechanical properties of the MWCNT/epoxy composites. The improved TS and EM of stretched composites proceeded from both increasing the MWCNT volume fraction and reducing the MWCNT waviness caused by 
stretching. TS and EM of the MWCNT sheets, their prepregs and composites, increased gradually with increasing MWCNT plies. TS and EM of the composites enhanced concomitantly with increasing the stretch ratio up to 3\%, but they decreased with the 4\% stretch ratio. With a 3\% stretch ratio, the MWCNT/epoxy composites achieved the best mechanical properties in this study. Hot stretching the prepregs at $100{ }^{\circ} \mathrm{C}$ produced higher TS and EM of the composites than those obtained at other temperatures. The effectiveness of the stretching the MWCNT sheets was higher than hot stretching their prepregs. In conclusion, stretching is extremely important for improving the mechanical properties of aligned MWCNT/epoxy composites.

\section{Acknowledgements}

We appreciate financial support by the Japan Science and Technology Agency (JST) through the Advanced Low Carbon Technology Research and Development Program (ALCA) and the Institute of Space and Astronautical Science (ISAS) through ISAS strategic development fund for space engineering.

\section{References}

[1] Iijima S. Helical microtubules of graphitic carbon. Nature 1991;354(6348):56-8.

[2] Dresselhaus M, Dresselhaus G, Avouris P. Carbon Nanotubes: Synthesis, Structure, Properties and Applications. New York: Springer, 2002.

[3] Reich S, Thomsen C, Maultzsch J. Carbon Nanotubes: Basic Concepts and Physical Properties. Weinheim: Wiley-VCH, 2004.

[4] Ruoff RS, Lorents DC. Mechanical and thermal properties of carbon nanotubes. Carbon 1995;33(7):925-30.

[5] Treacy MMJ, Ebbesen TW, Gibson JM. Exceptionally high Young's modulus observed for individual carbon nanotubes. Nature 1996;381:678-80. 
[6] Salvetat JP, Kulik AJ, Bonard JM, Forro L, Benoit W, Auppironi L. Mechanical properties of carbon nanotubes. Appl Phys A 1999;69(3):255-60.

[7] Yu MF, Lourie O, Dyer MJ, Moloni K, Kelly TF, Ruoff RS. Strength and breaking mechanism of multiwalled carbon nanotubes under tensile load. Science 2000; 287(5453):637-40.

[8] Ebbesen TW, Lezec HJ, Hiura H, Bennett JW, Ghaemi HF, Thio T. Electrical conductivity of individual carbon nanotubes. Nature 1996;382:54-6.

[9] Pop E, Mann D, Wang Q, Goodson K, Dai H. Thermal conductance of an individual single-wall carbon nanotube above room temperature. Nano Lett 2006;6(1):96-100.

[10]Coleman JN, Khan U, Blau WJ, Gun'ko YK. Small but strong: a review of the mechanical properties of carbon nanotube-polymer composites. Carbon 2006;44(9):1624-52.

[11]Thostenson ET, Ren Z, Chou TW. Advances in the science and technology of carbon nanotubes and their composites: a review. Compos Sci Technol 2001;61(13):1899-912.

[12] Rana S, Alagirusamy R, Joshi M. A review on carbon epoxy nanocomposites. J Reinf Plast Compos 2009;28(4):461-87.

[13] Gojny FH, Wichmann MHG, Kopke U, Fiedler B, Schulte K. Carbon nanotube reinforced epoxy-composites: enhanced stiffness and fracture toughness at low nanotube content. Compos Sci Technol 2004;64(15):2361-71.

[14]Guo P, Chen X, Gao X, Song H, Shen H. Fabrication and mechanical properties of well-dispersed multiwalled carbon nanotubes/epoxy composites. Compos Sci Technol 2007;67(15-16):3331-7.

[15]Huang H, Liu C, Wu Y, Fan S. Aligned carbon nanotube composite films for thermal management. Adv Mater 2005;17(13):1652-6. 
[16]Wardle BL, Saito DS, Garcia EJ, Hart AJ, Villoria RGD, Verploegen EA.

Fabrication and characterization of ultrahigh-volume-fraction aligned carbon nanotube-polymer composites. Adv Mater 2008;20(14):2707-14.

[17] Inoue Y, Kakihata K, Hirono Y, Horie T, Ishida A, Mimura H. One-step grown aligned bulk carbon nanotubes by chloride mediated chemical vapor deposition. Appl Phys Lett 2008;92(21):213113.

[18] Tibbetts GG, Lake ML, Strong KL, Rice BP. A review of the fabrication and properties of vapor-grown carbon nanofiber/polymer composites. Compos Sci Technol 2007;67(7-8):1709-18.

[19] Ghemes A, Minami Y, Muramatsu J, Okada M, Mimura H, Inoue Y. Fabrication and mechanical properties of carbon nanotube yarns spun from ultra-long multiwalled carbon nanotube arrays. Carbon 2012;50(12):4579-87.

[20] Spitalsky Z, Tsoukleri G, Tasis D, Krontiras C, Georga SN, Galiotis C. High volume fraction carbon nanotube-epoxy composites. Nanotechnology 2009;20(40):405702.

[21]Lopes PE, Hattum FV, Pereira CMC, Nóvoa PJRO, Forero S, Hepp F, et al. High CNT content composites with CNT buckypaper and epoxy resin matrix: impregnation behavior composite production and characterization. Compos Struct 2010;92(6):1291-8.

[22]Bradford PD, Wang X, Zhao H, Maria J-P, Jia Q, Zhu YT. A novel approach to fabricate high volume fraction nanocomposites with long aligned carbon nanotubes. Compos Sci Technol 2010;70(13):1980-5.

[23] Wang D, Song PC, Liu CH, Wu W, Fan SS. Highly oriented carbon nanotube papers made of aligned carbon nanotubes. Nanotechnology 2008;19(7):075609. 
[24]Zhang M, Fang S, Zakhidov AA, Lee SB, Aliev AE, Williams CD, et al. Strong, transparent, multifunctional, carbon nanotube sheets. Science 2005;309(5738):1215-9.

[25] Inoue Y, Suzuki Y, Minami Y, Muramatsu J, Shimamura Y, Suzuki K, et al. Anisotropic carbon nanotube papers fabricated from multiwalled carbon nanotube webs. Carbon 2011;49(7):2437-43.

[26] Cheng QF, Wang JP, Jiang KL, Li QQ, Fan SS. Fabrication and properties of aligned multiwalled carbon nanotube-reinforced epoxy composites. J Mater Res 2008;23(11):2975-83.

[27]Cheng QF, Wang JP, Wen JJ, Liu CH, Jiang KL, Li QQ, et al. Carbon nanotube/epoxy composites fabricated by resin transfer molding. Carbon 2010;48(1):260-6.

[28]Cheng QF, Bao J, Park J, Liang Z, Zhang C, Wang B. High mechanical performance composite conductor: multi-walled carbon nanotube sheet/bismaleimide nanocomposites. Adv Funct Mater 2009;19(20):3219-25.

[29] Ogasawara T, Moon SY, Inoue Y, Shimamura Y. Mechanical properties of aligned multi-walled carbon nanotube/epoxy composites processed using a hot-melt prepreg method. Compos Sci Technol 2011;71(16):1826-33.

[30]Wang X, Bradford PD, Liu W, Zhao H, Inoue Y, Maria JP, et al. Mechanical and electrical property improvement in CNT/Nylon composites through drawing and stretching. Compos Sci Technol 2011;71(14):1677-83. 
Fig. 1 - Processing of aligned MWCNT sheets ...

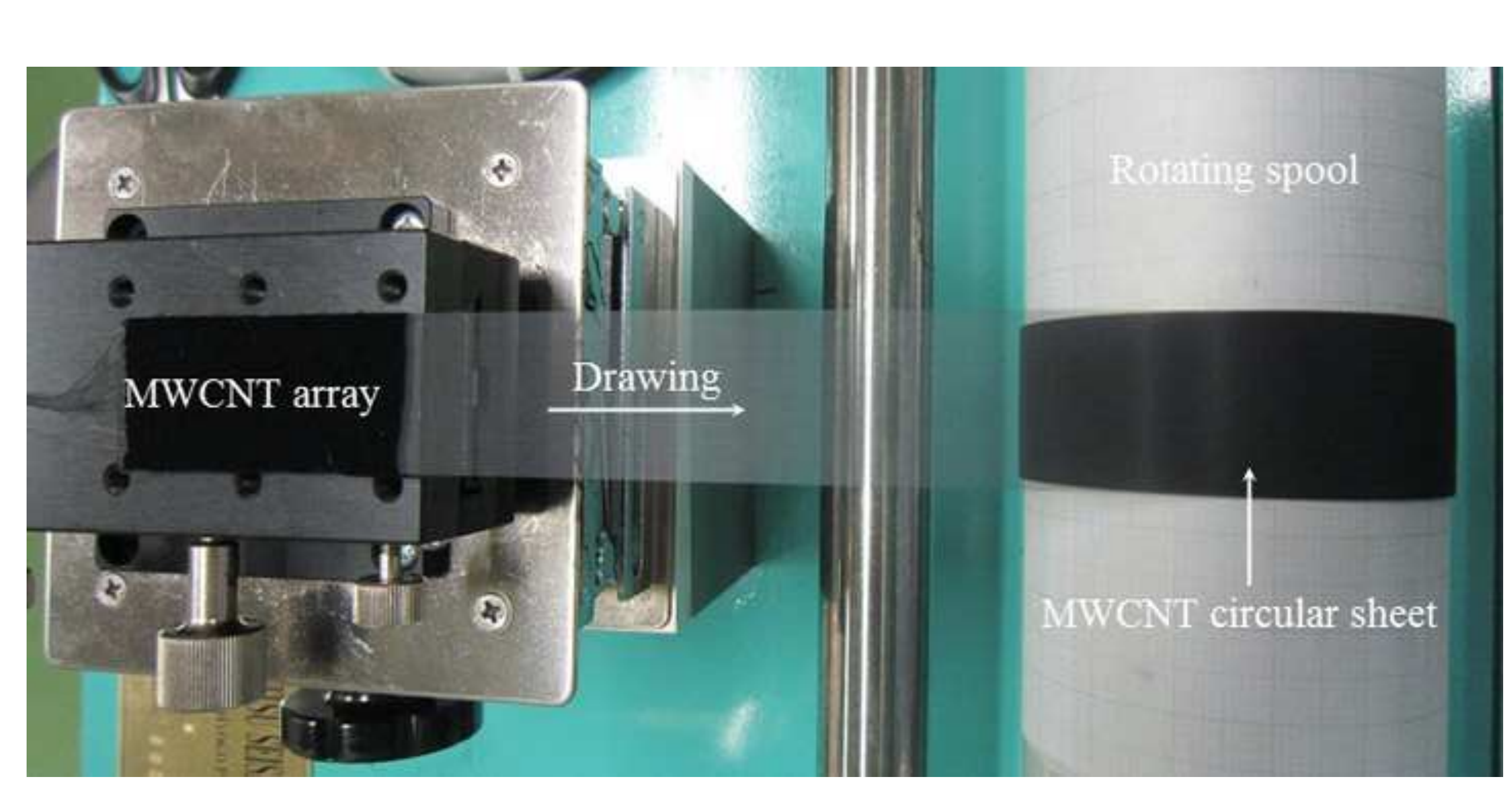




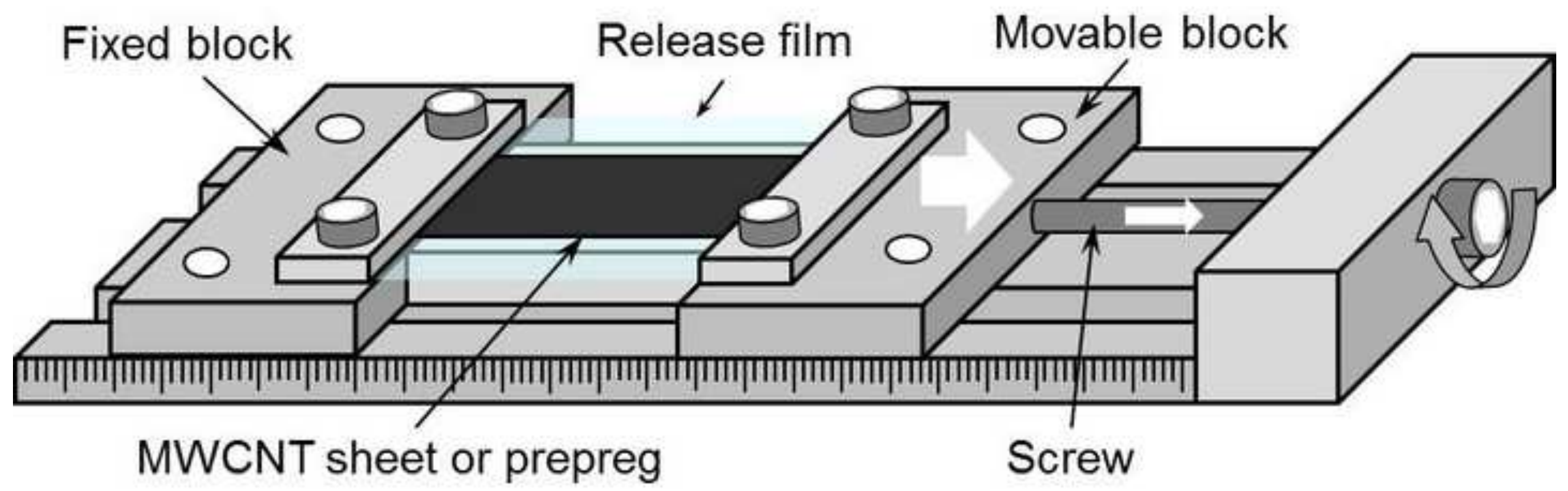



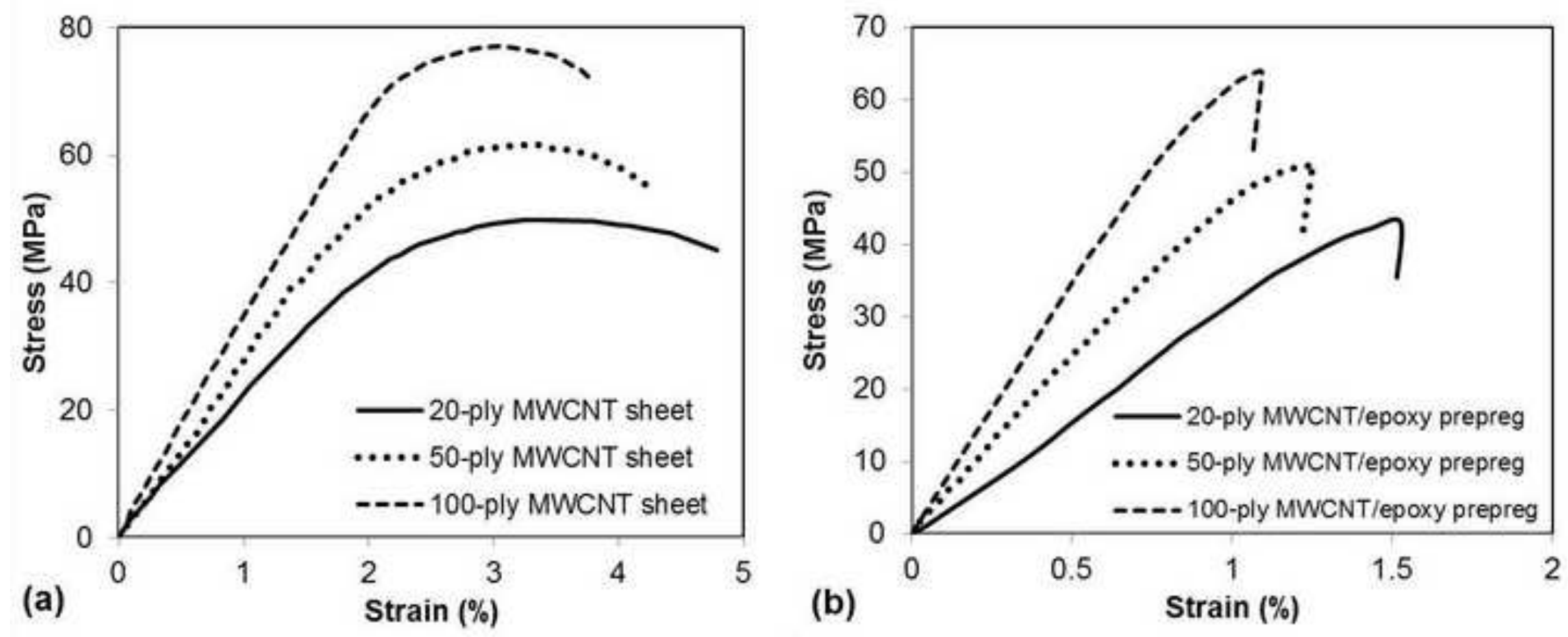
Fig. 4 - Effects of stretching the MWCNT sheets ...
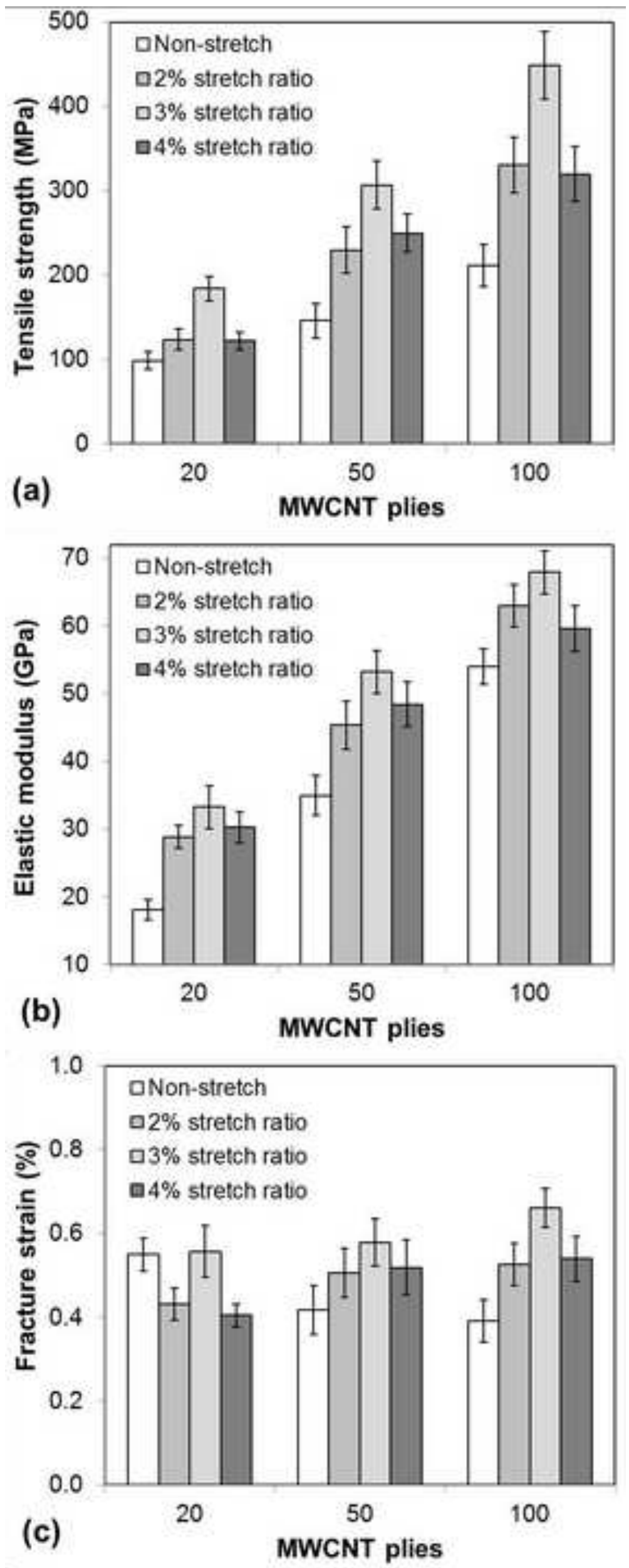
Fig. 5 - FE-SEM micrographs of (a) non-stretched MWCNT sheet ...
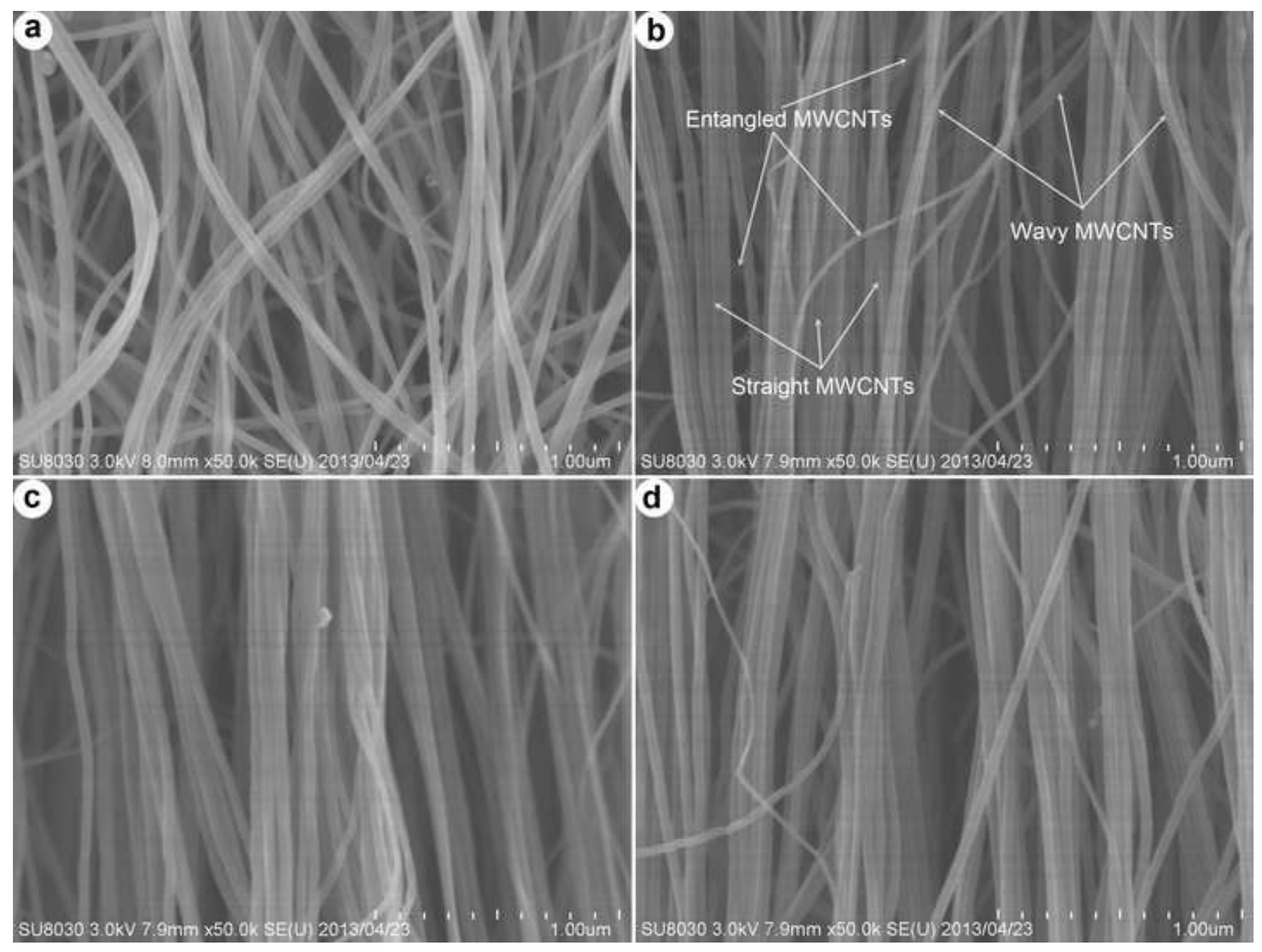


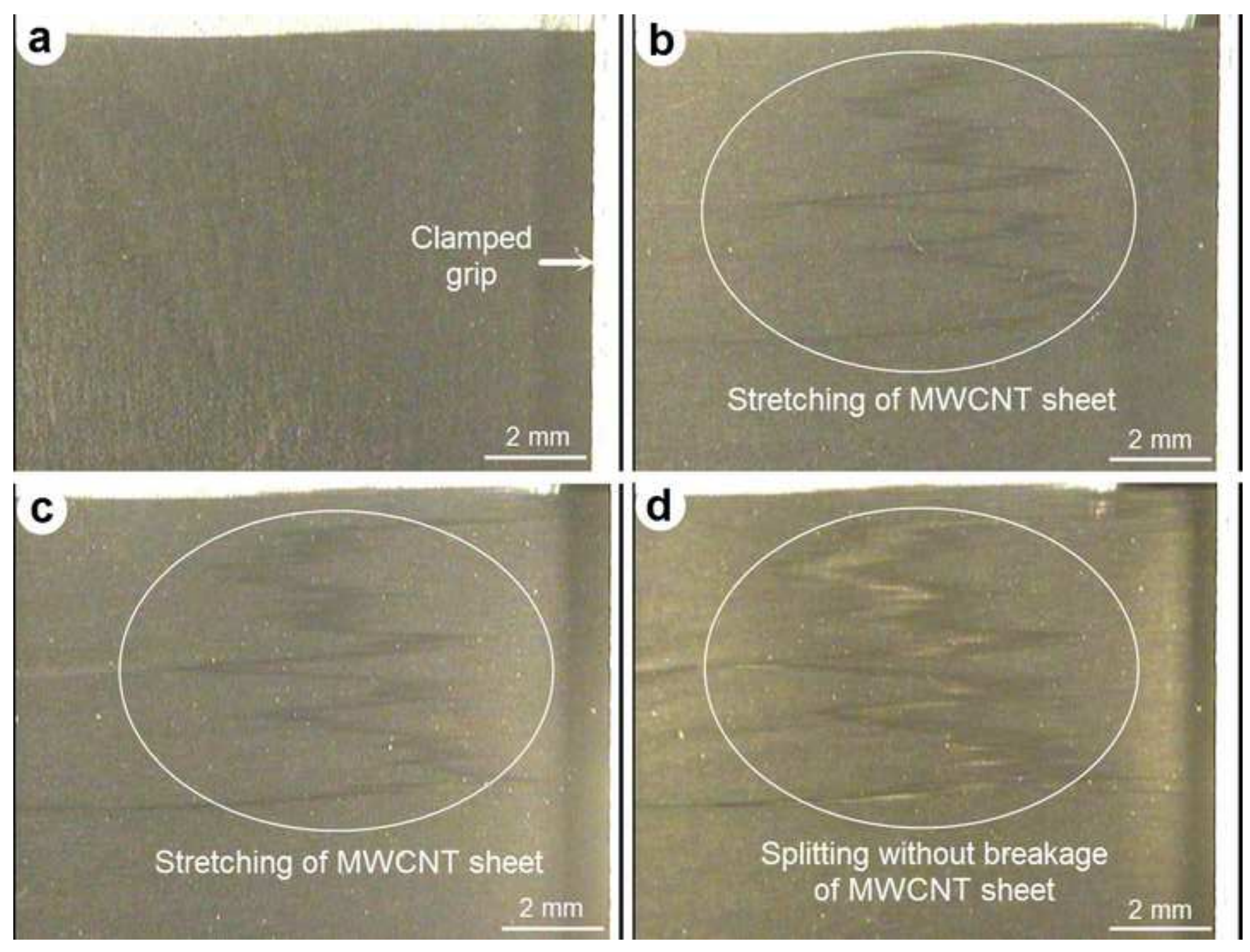




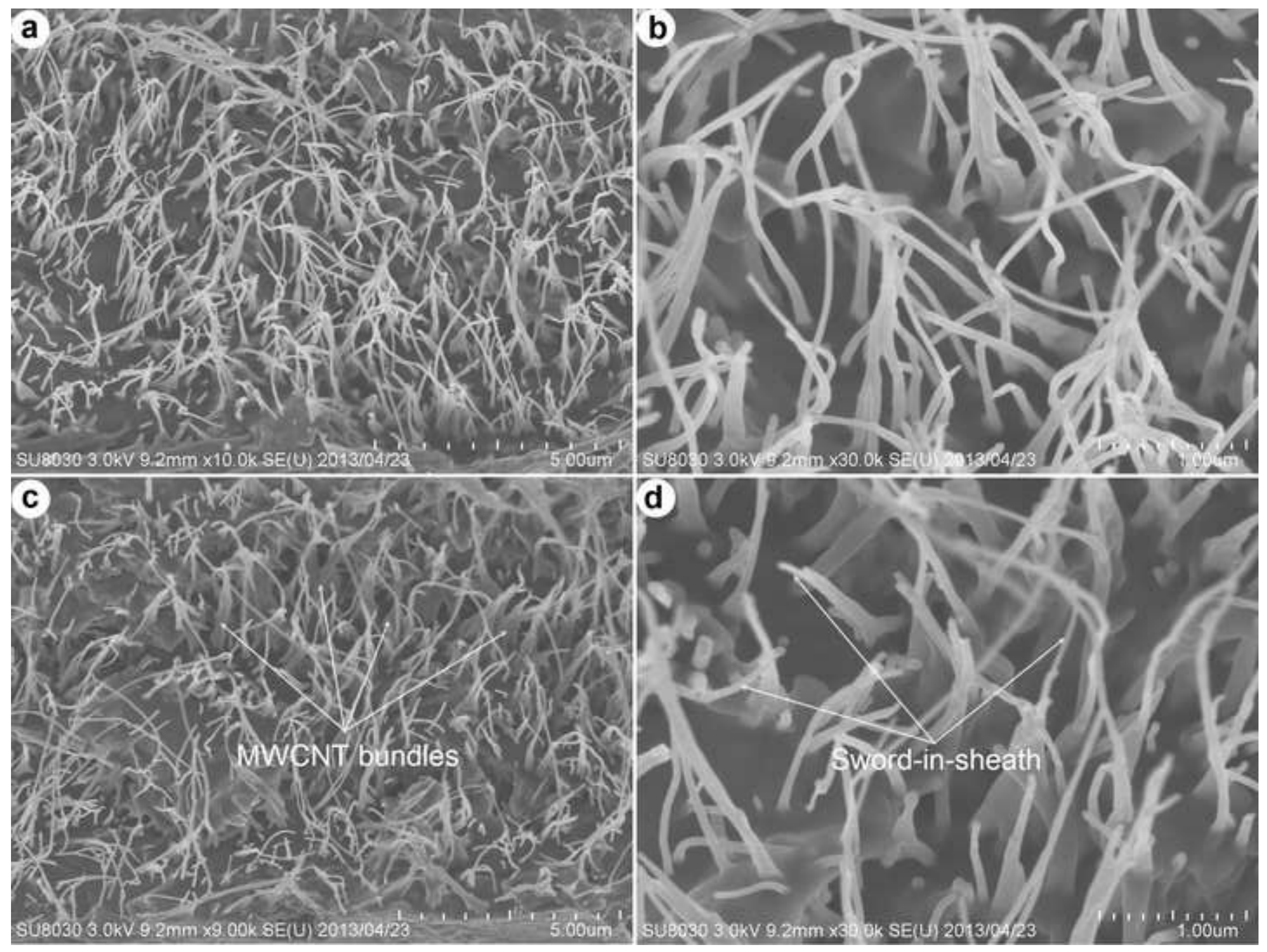


Fig. 9 - Effects of hot stretching MWCNT/epoxy prepregs ...
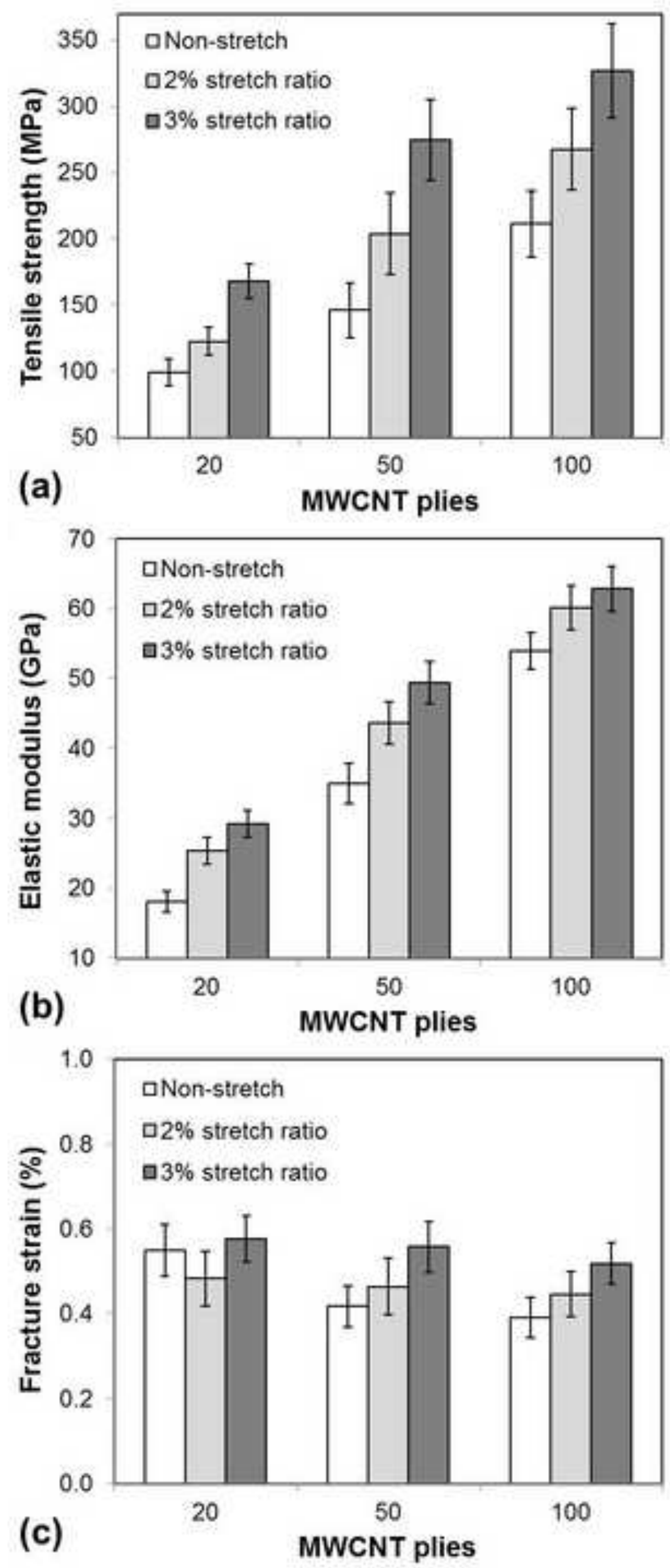
Fig. 10 - Percentage increase of EM and MWCNT volume fraction...



(a) Stretch ratios and MWCNT plies

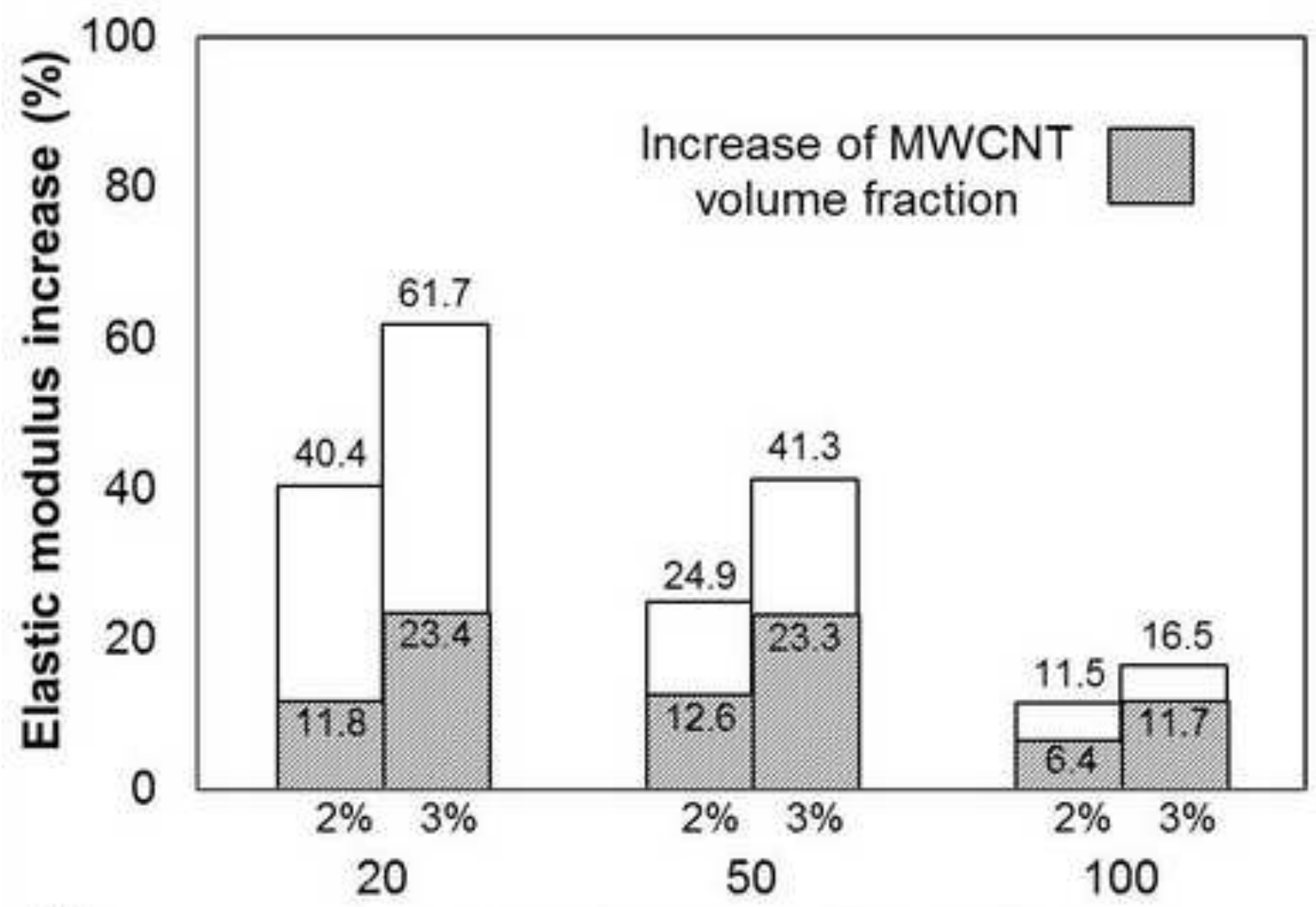

(b) Stretch ratios and MWCNT plies 


\begin{tabular}{|c|c|c|c|c|c|c|}
\hline \multirow{2}{*}{ Composite } & \multicolumn{3}{|c|}{ Thickness $(\mu \mathrm{m})$} & \multicolumn{3}{|c|}{ MWCNT volume fraction $(\%)$} \\
\hline & 20-ply & 50-ply & 100-ply & 20-ply & 50-ply & 100-ply \\
\hline Non-stretched & $9 \pm 1$ & $15 \pm 1$ & $18 \pm 1$ & 7.2 & 15.8 & 32.1 \\
\hline $2 \%$ stretched & $8 \pm 1$ & $13 \pm 1$ & $16 \pm 1$ & 8.3 & 18.1 & 34.6 \\
\hline $3 \%$ stretched & $7 \pm 1$ & $11 \pm 1$ & $15 \pm 1$ & 9.1 & 20.2 & 37.1 \\
\hline $4 \%$ stretched & $7 \pm 1$ & $11 \pm 1$ & $15 \pm 1$ & 9.4 & 20.5 & 37.5 \\
\hline $2 \%$ hot-stretched & $8 \pm 1$ & $13 \pm 1$ & $16 \pm 1$ & 8.0 & 17.8 & 34.2 \\
\hline $3 \%$ hot-stretched & $7 \pm 1$ & $12 \pm 1$ & $15 \pm 1$ & 8.9 & 19.5 & 35.8 \\
\hline
\end{tabular}




\begin{tabular}{|c|c|c|c|c|c|c|}
\hline \multirow{2}{*}{ Property } & \multicolumn{3}{|c|}{ MWCNT sheet } & \multicolumn{3}{|c|}{ MWCNT/epoxy prepreg } \\
\hline & 20-ply & 50-ply & 100-ply & 20-ply & 50-ply & 100-ply \\
\hline $\begin{array}{l}\text { Areal weight } \\
\left(\mathrm{g} / \mathrm{m}^{2}\right)\end{array}$ & 1.58 & 3.33 & 6.02 & 16.3 & 20.2 & 25.7 \\
\hline $\begin{array}{l}\text { Thickness } \\
(\mu \mathrm{m})\end{array}$ & $3 \pm 1$ & $7 \pm 1$ & $13 \pm 1$ & $13 \pm 1$ & $16 \pm 1$ & $18 \pm 1$ \\
\hline $\begin{array}{l}\text { Tensile strength } \\
(\mathrm{MPa})\end{array}$ & $52.7 \pm 1.6$ & $65.0 \pm 3.1$ & $79.0 \pm 3.1$ & $43.3 \pm 2.1$ & $50.3 \pm 3.8$ & $60.2 \pm 4.0$ \\
\hline $\begin{array}{l}\text { Elastic modulus } \\
(\mathrm{GPa})\end{array}$ & $2.29 \pm 0.2$ & $2.67 \pm 0.2$ & $3.50 \pm 0.2$ & $3.12 \pm 0.3$ & $4.19 \pm 0.4$ & $6.56 \pm 0.4$ \\
\hline $\begin{array}{l}\text { Strain at max stress } \\
(\%)\end{array}$ & $3.65 \pm 0.3$ & $3.27 \pm 0.1$ & $3.14 \pm 0.2$ & $1.58 \pm 0.1$ & $1.35 \pm 0.1$ & $1.12 \pm 0.1$ \\
\hline
\end{tabular}




\begin{tabular}{|c|c|c|c|c|c|}
\hline $\begin{array}{l}\text { MWCNT } \\
\text { plies }\end{array}$ & $\begin{array}{l}\text { Areal weight } \\
\qquad\left(\mathrm{g} / \mathrm{m}^{2}\right)\end{array}$ & $\begin{array}{l}\text { Density } \\
\left(\mathrm{g} / \mathrm{cm}^{3}\right)\end{array}$ & $\begin{array}{l}\text { Tensile strength } \\
\qquad(\mathrm{MPa})\end{array}$ & $\begin{array}{l}\text { Elastic modulus } \\
\qquad(\mathrm{GPa})\end{array}$ & $\begin{array}{c}\text { Fracture strain } \\
\qquad(\%)\end{array}$ \\
\hline $0^{*}$ & $\sim 12.0$ & 1.20 & $55.6 \pm 9.6$ & $2.6 \pm 0.2$ & $2.89 \pm 0.66$ \\
\hline 20 & 11.4 & 1.25 & $98.9 \pm 10.2$ & $18.1 \pm 1.5$ & $0.55 \pm 0.06$ \\
\hline 50 & 19.7 & 1.32 & $146.4 \pm 20.6$ & $35.0 \pm 2.9$ & $0.42 \pm 0.04$ \\
\hline 100 & 25.4 & 1.45 & $211.5 \pm 25.0$ & $54.0 \pm 2.6$ & $0.39 \pm 0.03$ \\
\hline
\end{tabular}

Epoxy resin 
Fig. 1 - Processing of aligned MWCNT sheets by drawing and winding MWCNT webs.

Fig. 2 - Schematic illustration of the stretching device with a mounted sample.

Fig. 3 - Stress-strain curves of (a) MWCNT sheets and (b) MWCNT/epoxy prepregs.

Fig. 4 - Effects of stretching the MWCNT sheets on mechanical properties of the resultant composites.

Fig. 5 - FE-SEM micrographs of (a) non-stretched MWCNT sheet and stretched MWCNT sheets with different ratios: (b) $2 \%$, (c) $3 \%$, and (d) $4 \%$.

Fig. 6 - Optical graphs showing surfaces of 20-ply MWCNT sheets before (a) and after stretching with ratios of (b) $2 \%$, (c) $3 \%$, and (d) $4 \%$.

Fig. 7 - FE-SEM micrographs showing tensile fracture surfaces of $(a, b)$ non-stretched and (c,d) 3\% stretched 100-ply MWCNT/epoxy composites.

Fig. 8 - Effects of hot stretching at different temperatures on TS and EM of the 20-ply MWCNT sheet reinforced epoxy composite.

Fig. 9 - Effects of hot stretching MWCNT/epoxy prepregs on mechanical properties of the resultant composites.

Fig. 10 - Percentage increase of EM and MWCNT volume fraction of (a) stretched and (b) hot-stretched composites compared with those of non-stretched ones. 
Table 1 - Thicknesses and MWCNT volume fractions of non-stretched and stretched composites

Table 2 - Properties of non-stretched MWCNT sheets and their prepregs

Table 3 - Properties of non-stretched MWCNT/epoxy composites 